\title{
Fornecimento de alimentação artificial para Apis mellifera
}

\author{
Artificial Apis mellifera feed supplementation \\ Suministro de alimentos artificiales para Apis mellifera
}

Recebido: 08/02/2021 | Revisado: 16/02/2021 | Aceito: 18/02/2021 | Publicado: 27/02/2021

Karine Aparecida Rodrigues de Souza

ORCID: https://orcid.org/0000-0002-7860-1047

Universidade Federal do Rio Grande do Sul, Brasil

E-mail: Karinerodriguesouza@hotmail.com

Daniel Emygdio de Faria Filho

ORCID: https://orcid.org/0000-0001-7148-1006

Universidade de São Paulo, Brasil

E-mail: fariafilho@usp.br

Sâmela Keila Almeida dos Santos

ORCID: https://orcid.org/0000-0003-4924-2687

Universidade Federal de Uberlândia, Brasil

E-mail: samela-zootecnia@hotmail.com

Lieska de Cassia Barbosa Passos

ORCID: https://orcid.org/0000-0002-1541-157X

Universidade Federal de Minas Gerais, Brasil E-mail: lieskabarbosa@gmail.com

Raquel Costa Palma

ORCID: https://orcid.org/0000-0003-4284-6939

Universidade Federal de Minas Gerais, Brasil E-mail: raquelcpalma@hotmail.com

Maria da Paixão do Nascimento

ORCID: https://orcid.org/0000-0003-2400-8923

Universidade Federal dos Vales do Jequitinhonha e Mucuri, Brasil

E-mail: maria.paixaorn@yahoo.com.br

Tatiana Cristina da Rocha

ORCID: https://orcid.org/0000-0002-1685-8234

Universidade Federal do Recôncavo da Bahia, Brasil

E-mail: tc.r@hotmail.com

Frederico Antonio Mineiro Lopes

ORCID: https://orcid.org/0000-0003-1878-3608

Universidade Federal de Minas Gerais, Brasil

E-mail: fredericomineiro@ica.ufmg.br

\begin{abstract}
Resumo
O objetivo do presente trabalho foi observar o desenvolvimento das colmeias, por meio do fornecimento da alimentação artificial para as mesmas e realizar a contagem de alvéolos de zangão, obreira, pólen e larvas. Os tratamentos experimentais foram: 1) xarope de açúcar; 2) xarope de açúcar e mel; 3) xarope proteico; 4) xarope invertido; 5) alimento pastoso. Os tratamentos foram distribuídos em delineamento em quadrado latino (5x5) com a utilização de 5 colmeias e 5 repetições geradas no tempo. Cada colmeia recebeu o tratamento durante o período de 21 dias e após esse período as colmeias permaneciam 15 dias sem o fornecimento de nenhum tratamento. Foram selecionados dois quadros de cada ninho, para a realização da contagem dos alvéolos, utilizando fotografias sobrepostas em quadro de mapeamento constituído de áreas de $4 \mathrm{~cm}^{2}$.Conclui-se que os tratamentos fornecidos não influenciaram na produção de alvéolos de zangão e obreira. O tratamento com xarope proteico influenciou no aumento do número de alvéolos de larvas e o tratamento com xarope de açúcar e mel foi significativo para a produção de alvéolos de pólen.
\end{abstract}

Palavras-chave: Abelhas; Alvéolos; Xarope.

\begin{abstract}
The aim of the present study was to observe bee hive development through artificial feed supplementation and carry out drone, worker, pollen and larvae alveoli counts. The experimental treatments consisted in 1) sugar syrup: 60\% sugar (crystal) $+40 \%$ water; 2) sugar and honey syrup: 60\% sugar (crystal) $+40 \%$ water, plus $100 \mathrm{~g}$ of honey; 3 ) protein syrup: $60 \%$ sugar and $40 \%$ water plus $20 \mathrm{~g}$ of soy flour; 4 ) inverted syrup: five kilos of crystal sugar +1.7 liters of water; 5) pasty food: three tablespoons of soy flour and seven tablespoons of wheat bran, adding about fifteen tablespoons of honey. The treatments were distributed in a Latin square design $(5 \times 5)$ using five hives and five repetitions generated over time. Each hive received one of the treatments during 21 days period, followed by a
\end{abstract}


treatment-free 15-day period. Two frames from each nest were selected to carry out the counting of the alveoli, using photographs overlaid on a mapping frame consisting of $4 \mathrm{~cm}^{2}$ areas. The treatments did not influence drone and worker alveoli production. The protein syrup treatment increased the number of larvae alveoli and the sugar and honey syrup treatment was significant for the production of pollen cells.

Keywords: Bees; Alveoli; Syrup.

\section{Resumen}

El objetivo del presente trabajo fue observar el desarrollo de las colmenas, mediante el suministro de alimentación artificial para ellas y realizar el conteo de alvéolos de zánganos, obreros, polen y larvas. Los tratamientos experimentales fueron: 1) jarabe de azúcar; 2) jarabe de azúcar y miel; 3) jarabe de proteína; 4) jarabe invertido; 5) comida pastosa. Los tratamientos se distribuyeron en un diseño de cuadrado latino $(5 \times 5)$ utilizando 5 colmenas y 5 repeticiones generadas en el tiempo. Cada colmena recibió tratamiento durante el período de 21 días y después de ese período las colmenas permanecieron 15 días sin proporcionar ningún tratamiento. Se seleccionaron dos cuadros de cada nido para el recuento de alvéolos, utilizando fotografías superpuestas en un marco de mapeo que consta de áreas de $4 \mathrm{~cm}^{2}$. Se concluyó que los tratamientos proporcionados no influyeron en la producción de pozos de drones y trabajadores. El tratamiento con jarabe de proteína influyó en el aumento del número de células larvarias y el tratamiento con jarabe de azúcar y miel fue significativo para la producción de células de polen.

Palabras clave: Abejas; Alvéolos; Jarabe.

\section{Introdução}

O sucesso da implantação e produção apícola depende das condições edafoclimáticas, que afetam o nicho ecológico das abelhas e podem levar a redução de suas populações. De maneira natural, as abelhas podem viver em enxames perdurados em galhos, ocos de árvores, cavidades no chão ou em telhados de residências. Nas criações comerciais, os enxames são alojados em colmeias, que são caixas apropriadas para otimizar a extração dos produtos desejados (Barbosa et al., 2007).

Em um enxame de Apis mellifera existe três tipos diferentes de castas de indivíduos: rainha, obreira e zangão, onde morfologicamente o maior indivíduo é a rainha, seguido pelo zangão e pela obreira (Gallo et al., 2002). O mecanismo básico de determinação das castas é regulado pela quantidade e qualidade do alimento na fase larval (Townsend \& Shuel, 1962; Jay, 1963; Rembold, 1964; Weaver, 1974; Beetsma, 1979).

Apesar da diversidade de produtos e serviços potenciais que podem ser explorados na apicultura, apenas colônias de Apis melífera povoadas e bem nutridas produzem mel, pólen, cera de abelha, geleia real, própolis e apitoxina em quantidades economicamente viáveis ou realizam serviços de polinização de forma satisfatória (vanEngelsdorp \& Meixner, 2010). Portanto, é de extrema importância promover o desenvolvimento e fortalecimento das colônias antes do período de produção ou floração das lavouras (Coelho et al., 2008; Evangelista-Rodrigues et al., 2008), utilizando assim técnicas de manejo, como alimentação artificial (Wiese, 2000).

Existe dois tipos de alimentação artificial, a de subsistência, rica em carboidratos, que é utilizada visando suprir a falta de alimento natural, em épocas de pouca florada e a estimulante, que é composta por substâncias proteicas e energéticas (Albanez, 2000). Estudos demonstraram que a utilização de uma dieta artificial como fonte de proteína, durante o inverno, pode induzir um aumento na população de crias e de abelhas operárias (Mattila \& Otis, 2006a; Akyol et al., 2006). O que não significa que existe uma época certa para a alimentação, uma vez que este período varia de acordo com a região e o objetivo da criação.

O presente estudo teve como objetivo observar e comparar o desenvolvimento entre colmeias de Apis mellifera ao receberem diferentes tipos de alimentação artificial.

\section{Metodologia}

\subsection{Local do experimento}

O experimento foi conduzido no período de 23 de abril a 4 de setembro de 2012, no Setor de Apicultura da Fazenda Experimental Professor Hamilton Abreu Navarro - FEHAN do Instituto de Ciências Agrárias da Universidade Federal de 
Minas Gerais, situado próximo às coordenadas geográficas: $16^{\circ} 40^{\prime} 42^{\prime \prime} \mathrm{S}$ e $43^{\circ} 50^{\prime} 31^{\prime \prime} \mathrm{W}$, com uma temperatura média anual de 22,65 ${ }^{\circ} \mathrm{C}$ e vegetação predominante de mistura entre cerrado e caatinga, na cidade de Montes Claros - MG.

\subsection{Alimentadores}

Foram utilizados quatro alimentadores semi-internos, do tipo bebedouro de alvado, modelo Boardman, para o fornecimento da alimentação estimulante liquida (Figura 1). A alimentação pastosa foi fornecida, através de uma sacola plástica, na qual foram realizados alguns furos sem dimensionamento, apenas para facilitar o acesso das abelhas à alimentação que permaneceu na melgueira (Figura 2).

Figura 1 - Bebedouro de alvado, modelo Boardman.

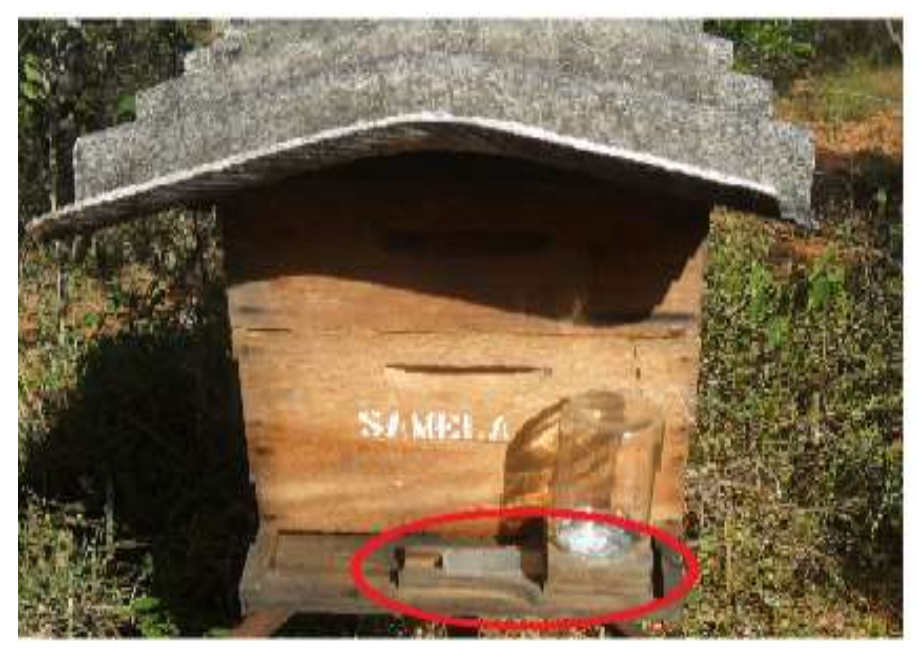

Fonte: Autores.

Figura 2 - Sacola plástica com alimentação pastosa.

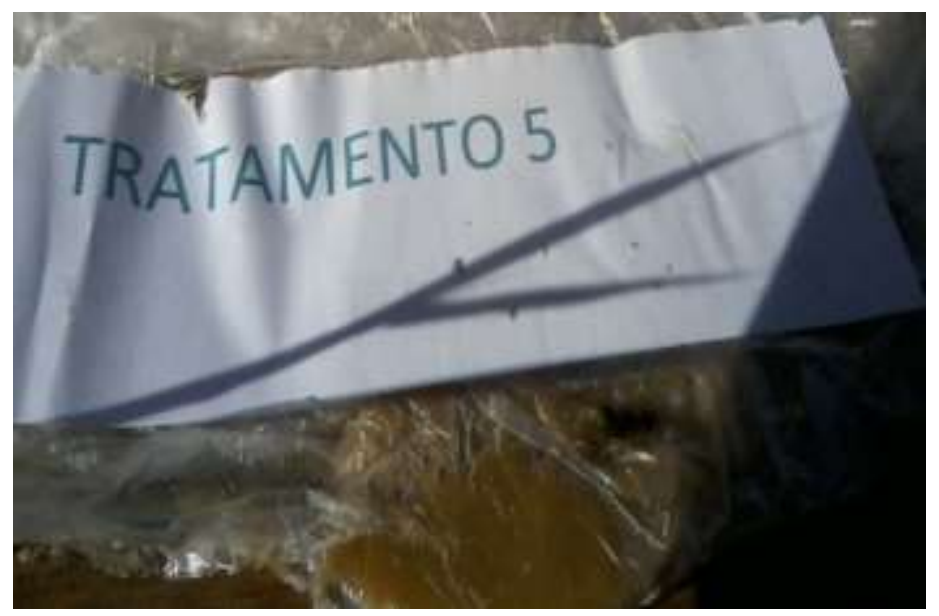

Fonte: Autores.

\subsection{Tratamento experimentais}

Foram fornecidos 5 tratamentos para as 5 colmeias, sendo 4 líquidos e 1 pastoso. Os alimentos líquidos foram fornecidos duas vezes por semana, na quantidade de $400 \mathrm{ml}$ (Kerr \& Amaral, 1960). O alimento pastoso foi fornecido apenas uma vez e permaneceu na colmeia durante os 21 dias do fornecimento da alimentação. Os tratamentos estudados foram:

Tratamento 1- Xarope de açúcar: $60 \%$ de açúcar (cristal) + 40\% de água. 
Tratamento 2- Xarope de açúcar com mel: 60\% de açúcar (cristal) + 40\% de água, acrescida de $100 \mathrm{~g}$ de mel.

Tratamento 3- Xarope proteico: $60 \%$ açúcar e $40 \%$ de água acrescida de $20 \mathrm{~g}$ de farinha de soja.

Tratamento 4- Xarope invertido: cinco quilos de açúcar cristal + 1,7 litros de água. Leva-se a mistura ao fogo baixo e quando começar a liberar vapor adiciona-se $5 \mathrm{~g}$ de ácido tartárico ou ácido cítrico e deixa-se em fogo baixo por 3 minutos.

Tratamento 5- Alimento pastoso: três colheres de sopa de farinha de soja e sete colheres de sopa de farelo de trigo, com cerca de quinze colheres de sopa de mel.

Cada colmeia recebeu uma alimentação artificial diferente durante o período de 21 dias. Após este permanecem em período de adaptação por 15 dias, para que a alimentação fornecida posteriormente não influenciasse nos efeitos da alimentação seguinte.

\subsection{Parâmetros avaliados}

Avaliou-se durante o fornecimento das diferentes alimentações artificiais, o desenvolvimento das colmeias. Por meio da contagem dos alvéolos de obreiras, zangão, pólen e larvas abertas. Foram selecionados dois quadros aleatórios de cada ninho. Os alvéolos dos quadros selecionados foram contados seguindo uma adaptação da metodologia de $\mathrm{Al}$ - Tikrity et al. (1971) para acompanhar o desenvolvimento dos alvéolos. A adaptação constituiu em fotografias sobrepostas de uma imagem com grades virtuais para obedecer à proporcionalidade de $4 \mathrm{~cm}^{2}$, independente da distância. As fotografias foram tiradas um dia antes dos 21 dias para o fornecimento das alimentações. A contagem dos alvéolos foi realizada por meio de um programa gratuito denominado OdoPlus, que conta os cliques do mouse, onde cada clique no respectivo alvéolo é contado, deixando assim as medidas mais precisas.

\subsection{Análise estatística}

Os tratamentos foram distribuídos em delineamento em quadrado latino (5x5) com 5 repetições geradas no tempo. Os dados foram submetidos à análise de variância por meio do programa SAS ${ }^{\circledR}$. Em caso de diferença significativa $(p<0,10)$ aplicou-se o teste de Duncan.

\section{Resultados e Discussão}

Os resultados dos tratamentos encontram-se presentes na Tabela 1, na qual pode-se verificar que não ocorreu diferença significativa entre os tratamentos e a produção de alvéolos de zangão (ZG) e obreira (OBR). Esses resultados podem ser explicados, pois na fase operculada que é o processo no qual as abelhas fecham os alvéolos de cria com uma fina camada de cera, a larva não se alimenta mais, todo o alimento necessário para o seu desenvolvimento já foi ingerido. Pois a determinação dos ovos que darão origem a obreiras ou zangões, acontece antes da ovulação (Ramos \& Carvalho, 2007). 
Tabela 1. Número de alvéolos de zangão (ZG), alvéolos de obreira (OBR), alvéolos de larva (LAR), alvéolos de pólen (PO) e total de alvéolos (TOT) com o fornecimento de diferentes tipos de alimentação artificial.

\begin{tabular}{lccccc}
\hline Tratamentos & ZG & OBR & LAR & PO & TOT \\
\hline 1 & $6,17 \mathrm{a}$ & $9,74 \mathrm{a}$ & $1,98 \mathrm{ab}$ & $2,66 \mathrm{~b}$ & $13,30 \mathrm{a}$ \\
& $(49,6)^{*}$ & $(112,4)$ & $(4,0)$ & $(7,7)$ & $(183,8)$ \\
2 & $4,70 \mathrm{a}$ & $5,36 \mathrm{a}$ & $1,65 \mathrm{ab}$ & $7,03 \mathrm{a}$ & $10,85 \mathrm{a}$ \\
& $(34,1)$ & $(39,2)$ & $(2,2)$ & $(50,8)$ & $(118,3)$ \\
3 & $7,44 \mathrm{a}$ & $9,31 \mathrm{a}$ & $2,61 \mathrm{a}$ & $5,04 \mathrm{ab}$ & $14,29 \mathrm{a}$ \\
& $(61,4)$ & $(121,5)$ & $(6,9)$ & $(32,7)$ & $(222,5)$ \\
4 & $5,07 \mathrm{a}$ & $8,05 \mathrm{a}$ & $1,08 \mathrm{~b}$ & $5,22 \mathrm{ab}$ & $12,67 \mathrm{a}$ \\
& $(35,4)$ & $(110,2)$ & $(0,2)$ & $(44,0)$ & $(189,8)$ \\
5 & $6,33 \mathrm{a}$ & $7,04 \mathrm{a}$ & $1,04 \mathrm{~b}$ & $2,26 \mathrm{~b}$ & $11,54 \mathrm{a}$ \\
& $(71,8)$ & $(74,6)$ & $(0,1)$ & $(5,9)$ & $(152,4)$ \\
\hline Análise de Variância & & & & & 0,42 \\
Tratamento & 0,80 & 0,25 & 0,06 & 0,11 & 0,04 \\
Tempo & 0,29 & 0,08 & 0,64 & 0,25 & 0,32 \\
Caixa & 0,15 & 0,04 & 0,42 & 0,71 & $\mathbf{2 8 , 0 9}$ \\
\hline CV (\%) & $\mathbf{6 4 , 3}$ & $\mathbf{5 5 , 4}$ & $\mathbf{4 9 , 4}$ & $\mathbf{6 3 , 0}$ & \\
\hline
\end{tabular}

*Os valores analisados foram transformados (raiz quadrada de $\mathrm{Y}+1$ ) e entre parênteses estão apresentadas as médias sem transformação. Médias seguidas por letras diferentes na coluna diferem estatisticamente entre si pelo teste de Duncan (10\%).

Fonte: Autores.

Ovos de obreiras e de zangões desenvolvem-se em células hexagonais, porém as que darão origem a zangões são visivelmente maiores e com aspecto mais arredondado (Barbosa et al., 2007). Na figura 3, pode-se observar a diferença entre as células de zangões e obreiras.

Figura 3 - Alvéolos de zangão e de obreira de Apis mellifera.

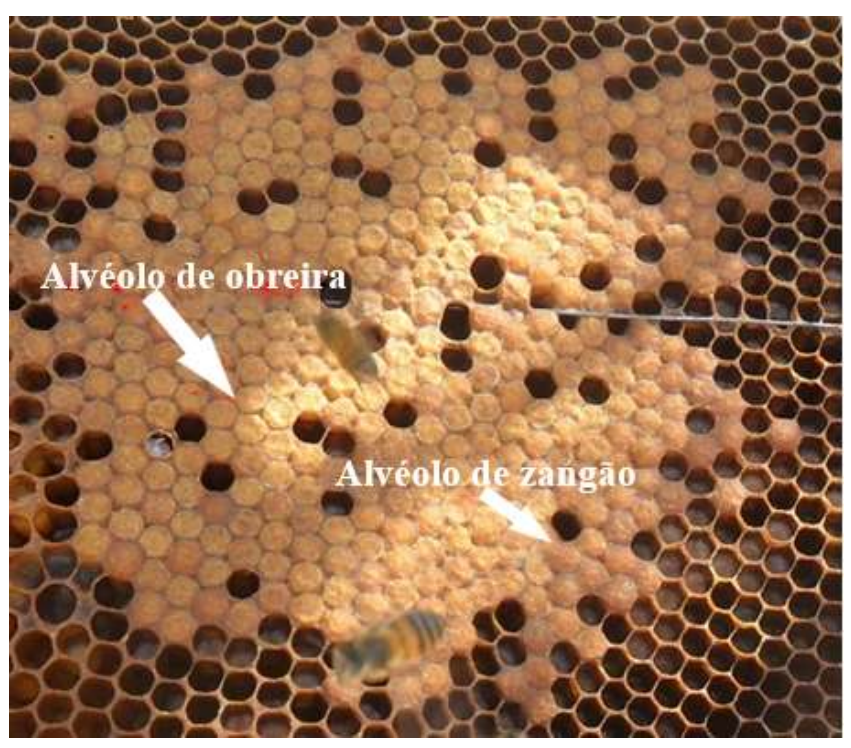

Fonte: Autores. 
Ocorreu diferença significativa para o Tratamento 3, favorecendo ao aumento da produção de larvas. Segundo Barker (1971) e Dreller e Tarpy (2000) a necessidade de pólen que é um alimento rico em proteínas para as abelhas e a sua necessidade na colmeia é regulada pela quantidade de cria aberta (larvas) por ele ser necessário para a sua alimentação. Provavelmente por esse motivo o Tratamento 3 obteve um desempenho superior comparado aos demais. Toda larva fêmea com menos de três dias de idade pode se desenvolver em obreira, ou rainha, dependendo da alimentação, fornecida pelas abelhas nutrizes. Esta diferenciação em rainha, ou obreira, depende dos níveis de hormônio juvenil, durante o período sensitivo, do desenvolvimento larval. A produção deste hormônio está relacionada com a quantidade e com a composição do alimento larval (Ramos \& Carvalho, 2007).

A nutrição na fase larval também pode afetar o comportamento e a fisiologia das obreiras. Mattila e Otis (2006b), obtiveram obreiras com vida mais longa em um ano e obreiras com vida mais curta em outro ano, quando suplementaram as colônias com proteína na primavera. O contraste entre os anos sugere que outros fatores além da nutrição proteica são responsáveis pelos seus resultados.

Para a produção de alvéolos de pólen, o Tratamento 2, apresentou desempenho superior. Segundo Haydak (1970) o pólen que é um dos constituintes da geleia real com a regurgitação de soluções do papo das operarias nutrizes que contêm principalmente açucares são responsáveis pela produção da geleia real. Devido a esse fato as abelhas passaram a consumir o tratamento com xarope de açúcar e mel, para aumentar a produção de geleia real, na colmeia.

\section{Conclusão}

Conclui-se que, o xarope proteico permitiu um melhor desenvolvimento dos alvéolos de larvas e o xarope de açúcar e mel aumentou a produção de pólen interferindo na produção de geleia real, para a manutenção das colmeias, ressaltando a importância em fornecer uma alimentação alternativa para as colônias no período de escassez.

\section{Referências}

Akyol, E., Yeninar, H., Sahinler, N., \& Guler, A. (2006). The effects of additive feeding and feed additives before wintering on honey bee colony performance, wintering abilities and survival rates at the East Mediterranean Region. Pakistan Journal of Biological Sciences, 9(4), 589-592. https://doi.org/10.3923/pjbs.2006.589.592

Albanez, J. R. (2000). Apicultura: manejo do apiário. EMATER-MG. Informe técnico. https://www.emater.mg.gov.br/doc/site/serevicosepro dutos/livraria/Agroind\%C3\%BAstria/Manejo\%20do\%20Api\%C3\%A1rio.pdf

Al-Tikrity, W. S., Hillmann, R.C., Benton, A. W., \& Clarke, W. W. (1971). A new instrument for brood measurement in a honey bee colony. American Bee Journal, Hamilton, 111 (1), 20-26.

Barbosa, A. de L., Pereira, F. de M., Vieira Neto, J. M., Rego, J. G. de S., Lopes, M. T. do R., \& Camargo, R. C. R. de. (2007). Criação de abelhas (apicultura). Brasília, DF: Embrapa Informação Tecnológica: Embrapa Meio-Norte. http://ainfo.cnptia.embrapa.br/digital/bits tream/item/11943/2/00081610.pdf

Barker, R. J. (1971). The influence of food inside the hive on pollen collection by a honeybee colony. Journal of Apicultural Research, 10 , 23-26. https://doi.org/10.1080/00218839.1971.11099666

Beetsma, J. (1979). The process of queen-worker differentiation in the honey bee. Bee World, 60, 24-39. https://doi.org/10.1080/0005772X.1979.11097727

Coelho, M. de S., Silva, J. H. V., Oliveira, E. R. A., Araújo, J. A., \& Lima, M. R. de. (2008). Alimentos convencionais e alternativos para abelhas. Caatinga. 21, 01-09. https://www.redalyc.org/pdf/2371/237117576033.pdf

Dreller, C., \& Tarpy, D. R. (2000). Perception of the pollen need by foragers in a honeybee colony. Animal Behaviour, 59(1), 9196. https://doi.org/10.1006/anbe.1999.1303

Evangelista-Rodrigues, A., Góis, G. C., Silva, C. M., Souza, D. L., Souza, D. N., Silva, P. C. C., Alves, E. L., \& Rodrigues, M. L. (2008). Desenvolvimento produtivo de colmeias de abelhas Melipona scutellaris. Biotemas. 21(1), 59-64. https://doi.org/10.5007/2175-7925.2008v21n1p59

Gallo, D., Nakano, O., Silveira Neto, S., Carvalho, R. P. L., Batista, G. C., Berti Filho, E., Parra, J. R. P., Zucchi, R. A., Alves, S. B., Vendramin, J. D., Marchini, L. C., Lopes, J. R. S., \& Omoto, C. (2002). Entomologia agrícola. Piracicaba: FEALQ.

Haydak, M. H. (1970) Honey Bee Nutrition. Annual Review of Entomology, 15(1), 143-156.https://doi.org/10 .1146/annurev.en.15.010170.001043 
Research, Society and Development, v. 10, n. 2, e53410212762, 2021 (CC BY 4.0) | ISSN 2525-3409 | DOI: http://dx.doi.org/10.33448/rsd-v10i2.12762

Jay, S. C. (1963). The development of honeybee in their cells. Journal of Apicultural Research. 2(2), 117-34. https://doi.org/10.1080/00218839.1963.11100072

Kerr, W. E., \& Amaral, E. (1960). Apicultura cienetífico e prática. Secretaria de Agricultura do Estado de Sâo Paulo, Diretoria de Publicações Agrícola.

Mattila, H. R., \& Otis, G. W. (2006b) The effects of pollen availability during larval development on the behaviour and physiology of spring-reared honey bee, Apidologie 37(5), 533-546. https://doi.org/10.1051/apido:2006037

Mattila, H. R., \& Otis, G. W. (2006a). Effects of pollen availability and Nosema infection during the spring on division of labor and survival of worker honey bees (Hymenoptera: Apidae). Environ Entomol, 35(3), 708-717. https://doi.org/10.1603/0046-225X-35.3708

Ramos, J. M., \& Carvalho, N. C. (2007). Estudo morfológico e biológico das fases de desenvolvimento de Apis mellifera. Revista Científica Eletrônica de Engenharia Florestal, 10(Vi), 21.

Rembold, H. (1964). Die Kastenentstehung bei der Honigbiene, Apis mellifica L. Die Naturwissenschaften, 51(3), 49-54. https://doi.org/10.1007/BF00603442

SAS. (2004). SAS Enterprise guide Software (9.1). Institute Inc. Cary.

Townsend, G. F., \& Shuel, R. W. (1962). Some recent advances in apicultural research. Annual Review of Entomology, 7(1), 481-500. https://doi.otg/10.1146/annurev.en.07.010162.002405

vanEngelsdorp, D., \& Meixner, M. D. (2010). A historical review of managed honey bee populations in Europe and the United States and the factors that may affect them. Journal of invertebrate Pathology. 103(1), S80-95. https://doi.org/10.1016/j.jip.2009.06.011

Weaver, N. (1974). Control of dimorphism in the female honeybee. 2. Methods of rearing larvae in the laboratory and preserving royal jelly. Journal of Apicultural Research, 13(1), 3-14. https://doi.org/10.1080/00218839.1974.11099752

Wiese, H. (2000). Apicultura - novos tempos: Livraria Editora Agropecuária 